\title{
Performance Comparison of Microstrip Band-Reject Filters for Different Dielectric Materials
}

\author{
Vivek Singh Kushwah, Geetam S. Tomar and Sarita Singh Bhadauria \\ Deptartment of Electronics, \\ Amity School of Engineering \& Technology, Gwalior, India, THDC Institute of \\ Hydropower Engg \& Technology, \\ Bhagirathipuram, Tehri, Tehri Garhwal, Uttarakhand 24913 India, Department of \\ Electronics Engg \\ MadhavInstitute of Technology and Science, Gwalior 474005 India \\ vivek_kushwah@rediffmail.com,gstomar@ieee.org,Saritamits61@gmail.com
}

\begin{abstract}
In this paper design of Microstrip band-reject filters have been presented for different dielectric materials on L-band applications. The various designs have also been compared with different dielectric constants and other performance parameters to check for viability and stability of designs on the considered frequency band. IE3D 14.1 simulation tool has been used for obtaining the Insertion loss and return loss performance of microstrip filter.
\end{abstract}

Keywords: Microstrip Filters, Return Loss, IE3D EM Simulation, Scattering parameters, Insertion Loss

\section{Introduction}

The present communication systems are going wireless at fast pace and need to have better quality of components, which are being used in wireless communication systems. Filters are one of the primary components used for selection of wanted signals to have communication with better performance. Microwave filters are commonly used for passing the desired band of frequencies and rejecting other frequencies for various modern microwave applications such as satellite-communication, Radar and mobile communication etc [1]. The work is focused on filter design, mathematical modeling of the filter designs along with the determining performance parameters like scattering parameters and losses. Almost every wireless communication systems have been brought in the microwave frequency range. In this range of frequency various active and passive components need to be fabricated with greater care and efficiency to obtain expected performance for better and efficient communication. The filters need much care and consideration as it is vital component in the communication systems to select the actual band of frequencies needed or need to be rejected, depending on the position of the filter in the communication system. Filters are an integral component of any microwave communication system. Filters are essential to perform task of separating, sorting of signals and impedance matching in communication systems [2]. Filters are also applicable in Radio Frequency front-ends as pre-select filters where pre-select filters select the desired frequency band. It is also highly recommended to have good quality of band reject filters with high insertion loss at its center frequency to reject selected pass band, which may be communicated in common media along with required base band [3]. In [3] microstrip dual-mode band reject filters using triangular patch resonators were investigated for the applications in microwave superconductivity, RF MEMS and LTCC technologies. In [4] compact left handed dual mode notch band stop filter has been 
proposed. The fabricated filter has the size of $11 \mathrm{~mm}$ x $50 \mathrm{~mm}$, at the center frequency of $1.12 \mathrm{GHz}$, which sometimes may be used for some specific application. There is also need for having high quality low/high pass filters at this range of frequency as to give better options of selection for various required or not required band of frequencies. Most of the communication systems require an RF front end LNA and filters processing elements for analog signal at the input [6]. This stage is an important stage in any communication system and needs high quality of filtering devices. The microstrip filters are generally used in transmitters and receivers at frequency ranges beyond $800 \mathrm{MHz}$. There have been many designs, which are proposed by researchers for various types of filters [5-12]. The basic design structure of the filters has been investigated by revisiting primary characteristics of the material and their applications according to the required applications and requirements. The design is considered with standard patch and modifications thereon for achieving parameters as desired. Various types of dielectric materials are proposed for the design of microstrip filters in L- band of frequencies on microstrip patch which have reduced filter size drastically and have given better option for various design considerations and options to have sharp cutoff, improved bandwidth and high performance filter design. In this work performance comparison of Microstrip band reject filter is presented for various dielectric materials.

\section{Fundamental Design of Microstrip Band- Reject Filters}

Band-reject filters can be designed using microstrip line [1-4]. These filters are having narrow-band and wide-band applications. The fundamental design of a band-reject filter with open-circuited stubs is shown in Figure 1 where the shunt quarter-wavelength and open-circuited stubs are separated by unit elements (connecting lines) that are a quarter wavelengths long at the mid-stop-band frequency. Filtering characteristics of the filter then entirely depends on design of characteristic impedances $Z i$ for the open-circuited stubs, and characteristic impedances $Z_{i, i+1}$ for the unit elements, as well as two terminating impedances $Z_{A}$ and $Z_{B}$.

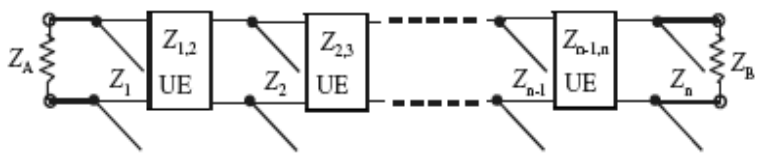

(a)

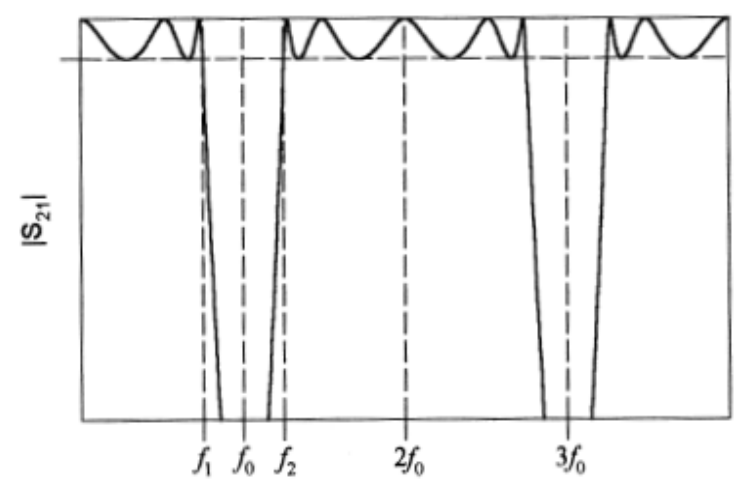

(b)

Figure 1. Band-Stop Filter with Open-Circuited Stubs. (a) Basic Design of Filter using Transmission line $(b)$ Insertion Loss Versus FreQUENCY Characteristic of Filter 
First step for designing of such type of filter is to find out the dimensions of filter using microstrip line design equations by performing some mathematical modeling [1]. For determining the bandwidth of filter, fractional bandwidth $(F B W)$ is used which is represented in mathematical form by equation (1).

$$
F B W=\frac{f_{2-} f_{1}}{f_{0}}
$$

$f_{0}$ is the mid-stop-band frequency of the corresponding band-stop filter. $f_{1}$ and $f_{2}$ are the corner frequencies. Element values of band-reject filters for 3-pole $(n=3)$ open circuited stubs are given in table $1[1]$.

Table 1. Prototype Parameters of Band-Reject Filters for Passband Ripple Constant $(\varepsilon)$ of 0.1005 for Three Open Stubs

\begin{tabular}{|cccc|}
\hline$F B W$ & $g_{1}=g_{3}$ & $g_{2}$ & $J_{1,2}=J_{2,3}$ \\
\hline 0.3 & 0.16318 & 0.26768 & 0.97734 \\
0.4 & 0.23016 & 0.38061 & 0.92975 \\
0.5 & 0.37754 & 0.63292 & 0.83956 \\
0.6 & 0.46895 & 0.79494 & 0.78565 \\
0.7 & 0.56896 & 0.97488 & 0.73139 \\
0.8 & 0.67986 & 1.17702 & 0.67677 \\
0.9 & 0.80477 & 1.40708 & 0.62180 \\
1.0 & 0.94806 & 1.67311 & 0.56648 \\
1.1 & 1.11601 & 1.98667 & 0.51082 \\
1.2 & 1.15215 & 2.06604 & 0.49407 \\
1.3 & 1.37952 & 2.49473 & 0.43430 \\
1.4 & 1.67476 & 3.05136 & 0.37349 \\
1.5 & 2.07059 & 3.79862 & 0.31262 \\
\hline
\end{tabular}

The tabulated elements are the normalized admittances, and for a given reference impedance $Z_{0}$, the line impedances are determined by

$$
\begin{gathered}
Z_{A}=Z_{B}=Z_{0} \\
Z_{i}=Z_{0} / g_{i} \\
Z_{i, i+1}=Z_{0} / J_{i, i+1}
\end{gathered}
$$

An optimum microstrip band-reject filter with three open-circuited stubs $(n=3)$ and a fractional bandwidth $F B W$ of 0.5 at a mid stop band frequency $\left(f_{0}\right) 1.8 \mathrm{GHz}$ has been designed. From Table 1, the normalized element values have obtained which are $g_{1}=g_{3}=$ $0.3774, g_{2}=0.63292$, and $J_{1,2}=J_{2,3}=0.83956$. The filter is designed to match $50 \Omega$ terminations. Therefore, $Z 0=50 \mathrm{ohms}$, and the Connecting line impedance for the filter network representation has been calculated by using equation (2).

$$
\begin{gathered}
Z_{A}=Z_{B}=Z_{0}=50 \Omega \\
Z_{1}=Z_{3}=132.43 \Omega \\
Z_{2}=78.998 \Omega \\
Z_{1,2}=Z_{2,3}=59.55 \Omega
\end{gathered}
$$

Here $Z_{1}, Z_{2}, Z_{3}$ are Stub line impedance and $Z_{0}, Z_{1,2}$ and $Z_{2,3}$ are Connecting line impedance. Dimensions of open circuited stubs and connecting lines are determined using microstrip line design equations for different impedances values and dielectric constants. In this paper, three different types of dielectric materials are used for microstrip filter design and performance of the microstrip filters are compared for different dielectric substrate. 


\section{Performance Comparison of Microstrip Band- Reject Filters}

Three Dielectric materials are mostly used as a substrate for fabrication of Microstrip filters.

(1) RT/Duroid 6010 LM which has Dielectric Constant $\left(\varepsilon_{\mathrm{r}}\right)$ of 10.2 ,

Thickness $(\mathrm{h})=0.635 \mathrm{~mm}$, Loss tangent $(\delta)=0.0023$

(2) Dielectric Material FR4 Substrate which has the following properties : Dielectric Constant $\left(\varepsilon_{\mathrm{r}}\right)=4.4$, Thickness $(\mathrm{h})=1.6 \mathrm{~mm}$, Loss tangent $(\delta)=0.02$

(3) RT/Duroid 6006: Dielectric Constant $\left(\varepsilon_{\mathrm{r}}\right)=6.15$, Thickness $(\mathrm{h})=1.27 \mathrm{~mm}$, Loss tangent $(\delta)=0.0027$

(1) For Dielectric Material RT/Duroid 6010 LM: It has Dielectric Constant $\left(\varepsilon_{\mathrm{r}}\right)=10.2$, Thickness $(\mathrm{h})=0.635 \mathrm{~mm}$, Loss tangent $(\delta)=0.0023$

The widths and quarter guided wavelengths linked with the characteristic admittances of microstrip line can be derived with the help of designed equations and are summarized in Table 2.

Table 2. Basic Design Parameters of First Microstrip Filter

\begin{tabular}{|c|c|c|}
\hline Line Impedance & $\begin{array}{c}\text { Line width } \\
\mathbf{W}(\mathbf{m m})\end{array}$ & Quarter guided wavelength $\mathbf{L}=\boldsymbol{\lambda g 0 / 4 ( m m )}$ \\
\hline $\mathrm{Z} 1 \& \mathrm{Z} 3$ & $\mathrm{~W} 1=\mathrm{W} 3=0.02$ & $\mathrm{~L} 1=\mathrm{L} 3=17.44$ \\
\hline $\mathrm{Z} 2$ & $\mathrm{~W} 2=0.2$ & $\mathrm{~L} 2=16.67$ \\
\hline $\mathrm{Z} 1,2 \& \mathrm{Z} 2,3$ & $\mathrm{~W} 1,2=\mathrm{W} 2,3=0.4$ & $\mathrm{~L} 1,2=\mathrm{L} 2,3=16.32$ \\
\hline $\mathrm{ZA} \& \mathrm{ZB}$ & $\mathrm{W} 0=0.59$ & \\
\hline
\end{tabular}

The basic design of microstrip filter is shown in Figure 2 which is obtained by using some mathematical calculations with the help of design equations for microstrip filter and plotted by using IE3D electromagnetic simulation software. It consists of three stubs of quarter guided wavelength long linked with each other with the help of connecting microstrip lines. The $50 \mathrm{ohm}$ terminating microstrip line is used for connecting the 50 ohm load/port so that input is provided to the microstrip filter through input port and output characteristics response is measured from the output port. The total area of the proposed design of microstrip filter is $678.65 \mathrm{~mm}^{2}$ which is more compact as compared to existing designs [2-8]. Length of the proposed filter is $37.64 \mathrm{~mm}$ and width of the proposed filter is $18.03 \mathrm{~mm}$.

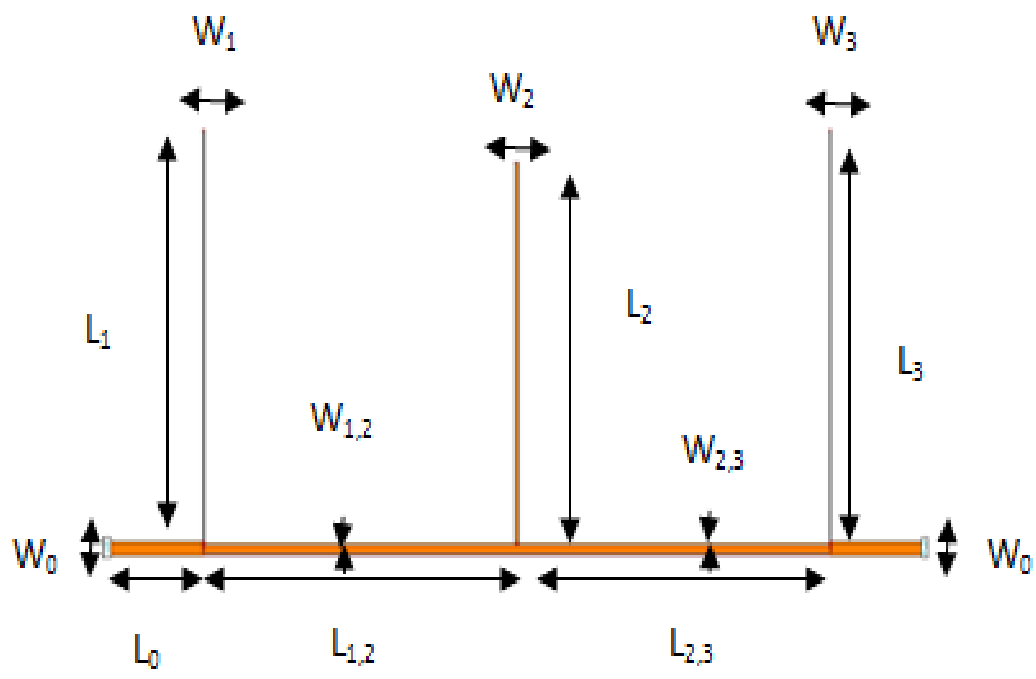

Figure 2. Fundamental Design of First Microstrip Filter for RT/Duroid 6010 LM 
(2) For Dielectric Material FR4 Substrate: This material has the following properties: Dielectric Constant $(\varepsilon \mathrm{r}=4.4)$, Thickness $\mathrm{h}=1.6 \mathrm{~mm}$, Loss tangent $(\delta)=0.02$

Table 3 represents the basic design parameters of microstrip band-reject filter for FR4 dielectric substrate.

Table 3. Basic Design Parameters of Second Microstrip Filter

\begin{tabular}{|c|c|c|}
\hline Line Impedance & $\begin{array}{c}\text { Line width } \\
\mathbf{W}(\mathbf{m m})\end{array}$ & Quarter guided wavelength $\mathbf{L}=\lambda \mathbf{g 0 / 4}(\mathbf{m m})$ \\
\hline $\mathrm{Z} 1 \& \mathrm{Z3}$ & $\mathrm{W} 1=\mathrm{W} 3=0.3$ & $\mathrm{~L} 1=\mathrm{L} 3=24.68$ \\
\hline $\mathrm{Z} 2$ & $\mathrm{~W} 2=1.55$ & $\mathrm{~L} 2=23.66$ \\
\hline $\mathrm{Z} 1,2 \& \mathrm{Z} 2,3$ & $\mathrm{~W} 1,2=\mathrm{W} 2,3=2.3$ & $\mathrm{~L} 1,2=\mathrm{L} 2,3=23.32$ \\
\hline $\mathrm{ZA} \& \mathrm{ZB}$ & $\mathrm{W} 0=3.1$ & \\
\hline
\end{tabular}

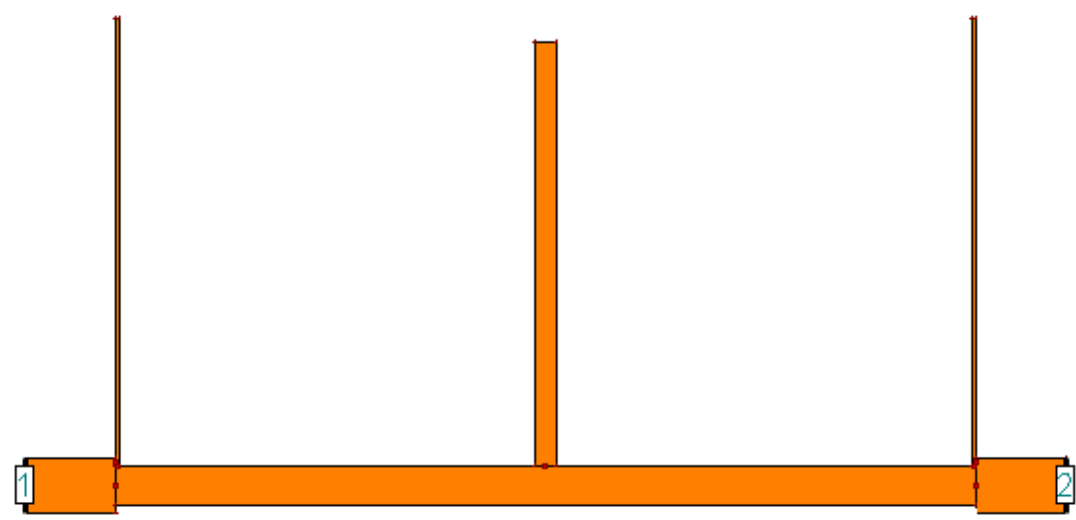

Figure 3. Fundamental Design of Second Microstrip Filter with Stubs

(3)For RT/Duroid 6006 Dielectric Substrate: This dielectric material has the following properties:

Dielectric Constant $\left(\varepsilon_{\mathrm{r}}\right)=6.15$, Thickness $(\mathrm{h})=1.27 \mathrm{~mm}$, Loss tangent $(\delta)=0.0027$

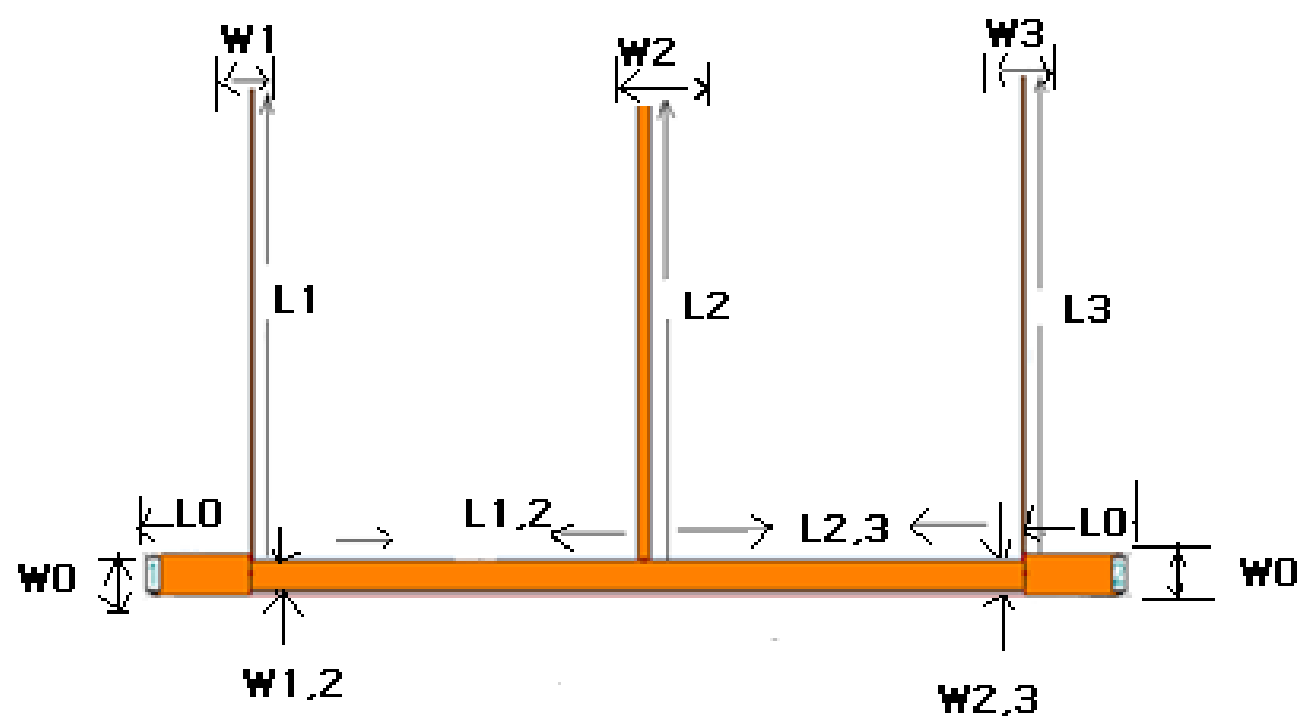

Figure 4. Fundamental Design of Third Microstrip Filter with Stubs 
Table 4 illustrates the basic design parameters of microstrip band-reject filter for RT/Duroid 6006 dielectric substrate.

Table 4. Basic Design Parameters of Third Microstrip Filter

\begin{tabular}{|c|c|c|}
\hline Line Impedance & $\begin{array}{c}\text { Line width } \\
\text { W(mm) }\end{array}$ & $\begin{array}{c}\text { Quarter guided } \\
\text { wavelength } \mathbf{L}=\lambda \mathbf{g 0 / 4}(\mathbf{m m})\end{array}$ \\
\hline $\mathrm{Z} 1 \& \mathrm{Z} 3$ & $\mathrm{~W} 1=\mathrm{W} 3=0.13$ & $\mathrm{~L} 1=\mathrm{L} 3=21.36$ \\
\hline $\mathrm{Z} 2$ & $\mathrm{~W} 2=0.72$ & $\mathrm{~L} 2=20.52$ \\
\hline $\mathrm{Z} 1,2 \& \mathrm{Z} 2,3$ & $\mathrm{~W} 1,2=\mathrm{W} 2,3=1.35$ & $\mathrm{~L} 1,2=\mathrm{L} 2,3=20.06$ \\
\hline $\mathrm{ZA} \& \mathrm{ZB}$ & $\mathrm{W} 0=1.87$ & $\mathrm{~L} 0=5$ \\
\hline
\end{tabular}

\section{Implementation and Results}

Figure 5 illustrates the frequency response of microstrip band reject filter for the dielectric material RT/Duroid $6010 \mathrm{LM}$ which shows the bandwidth of the filter ranges from 1.3 to $2.3 \mathrm{GHz}$ for L--band applications.

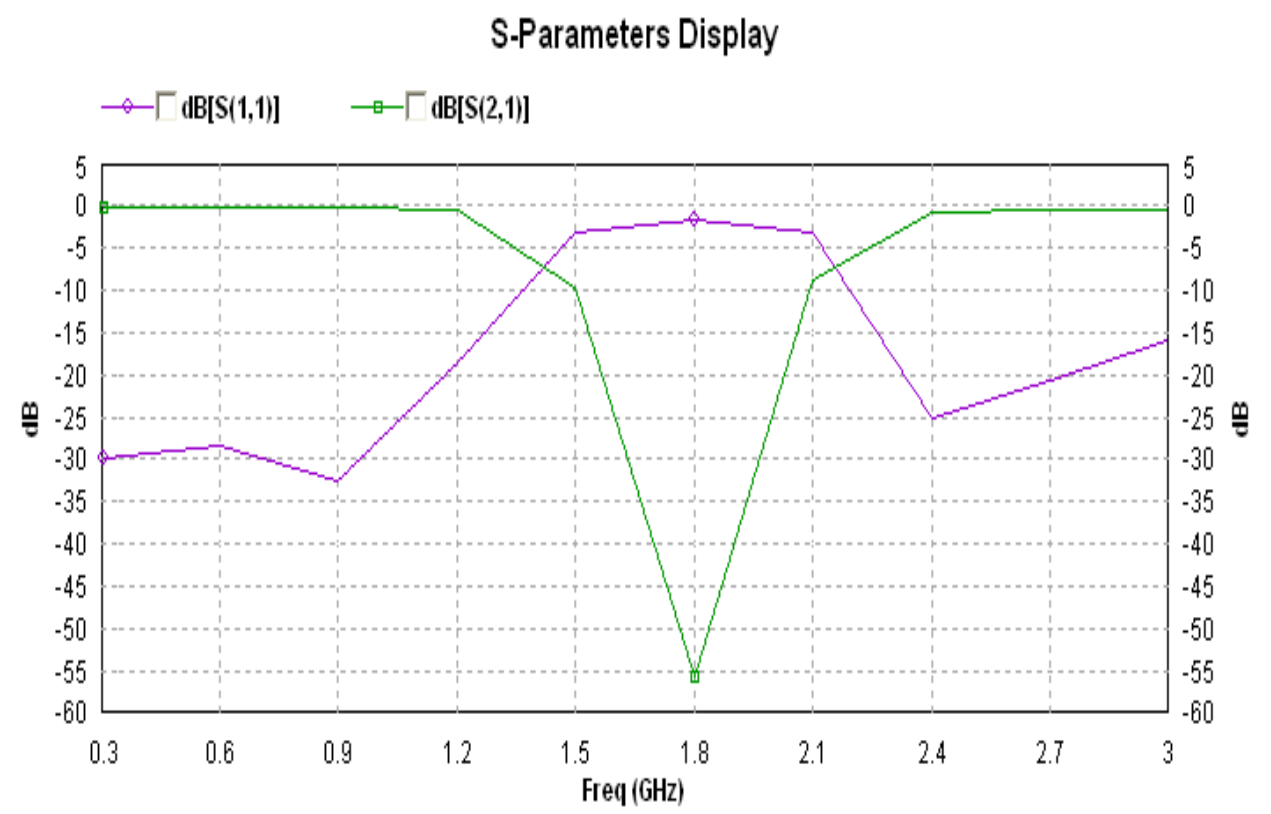

Figure 6. IE3D EM Simulated Performance of the First Microstrip BandReject Filter for RT/Duroid 6010 LM Dielectric Substrate

Performance of the filter is measured in terms of return- loss and insertion-loss which is measured in the form of $\mathrm{S}$ - parameters $\left(\mathrm{S}_{11}, \mathrm{~S}_{21}\right)$. Figure 7 shows the frequency response of microstrip band reject filter for the dielectric material FR4 Substrate, which shows the bandwidth of the filter, ranges from 1.25 to $2.35 \mathrm{GHz}$ for mobile communication. It has very low return loss and high insertion loss as compared to previous design. 


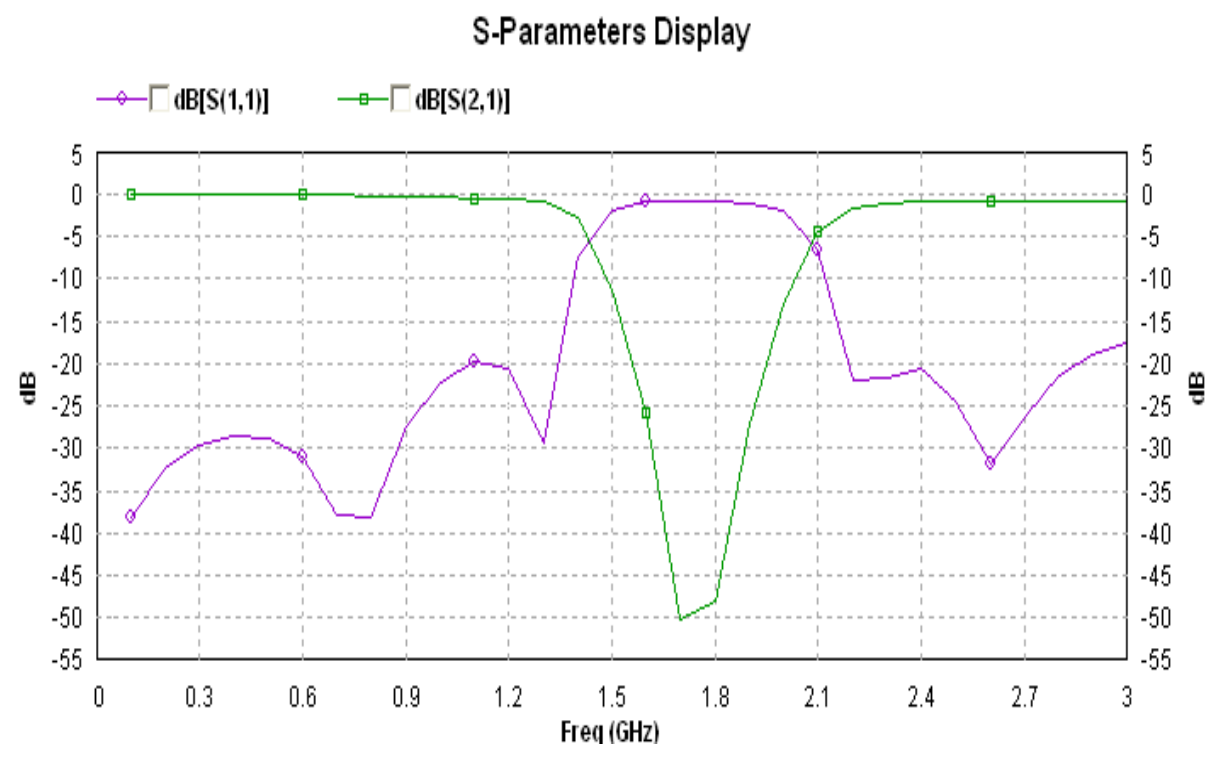

Figure 7. IE3D EM Simulated Performance of the Second Microstrip BandReject Filter for Glass Epoxy FR4 Dielectric Substrate

Figure 8 illustrates the frequency versus return/ insertion loss response of microstrip band-reject filter for the dielectric material RT/Duroid 6006 Substrate which shows the bandwidth of the filter ranges from 1.4 to $2.2 \mathrm{GHz}$ for narrowband application. It also has very low return loss and high insertion loss as compared to previous design.

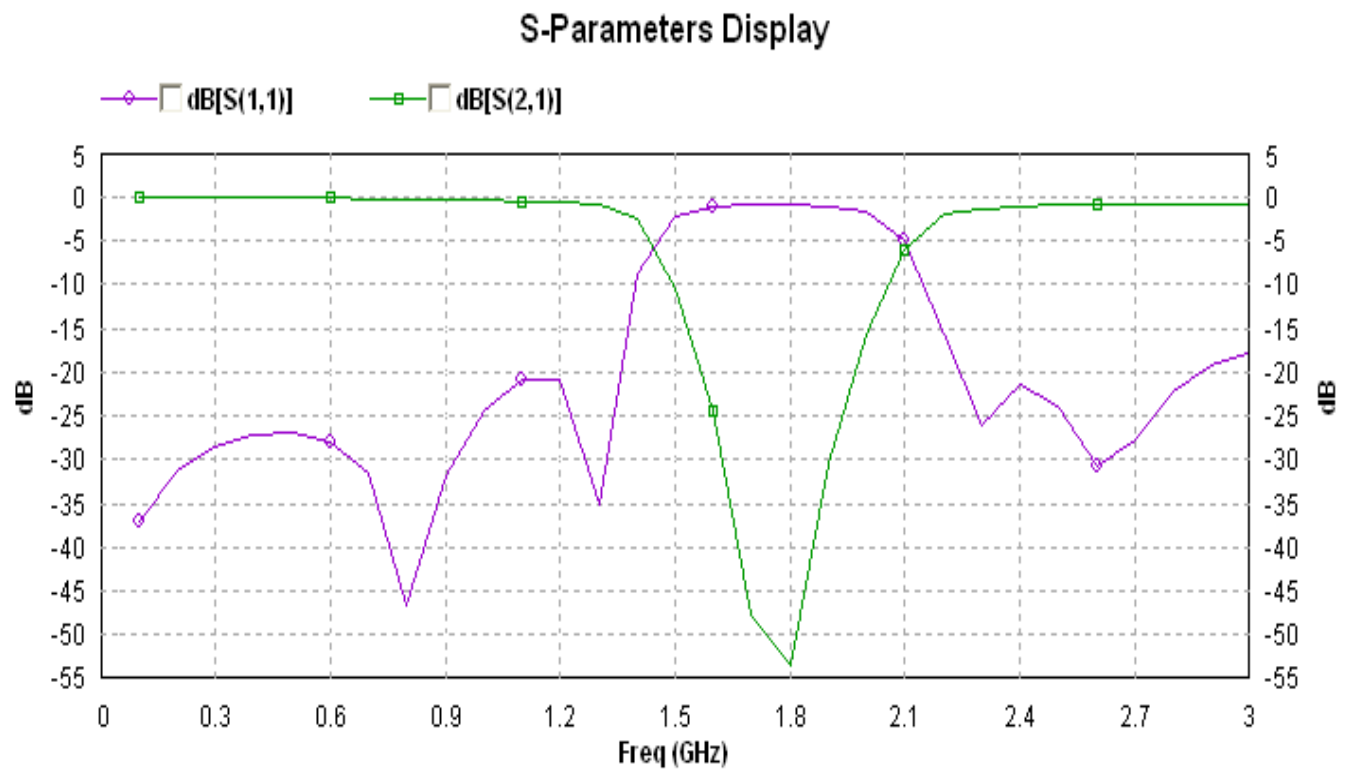

Figure 8. IE3D EM Simulated Performance of the Second Microstrip BandReject Filter for RT/Duroid 6006 Dielectric Substrate

Table 3 represents the performance comparison of microstrip filter in terms of return and insertion loss for various dielectric substrates. 
Table 5. Performance Comparison of Microstrip Filter for different Substrate

\begin{tabular}{|c|c|c|c|}
\hline Material/Substrate & $\begin{array}{c}\text { Return loss in } \\
\mathrm{dB}\end{array}$ & $\begin{array}{c}\text { Insertion Loss in } \\
\mathrm{dB}\end{array}$ & Bandwidth \\
\hline RT/Duroid 6010 LM & $-1.663 \mathrm{~dB}$ & $-55.73 \mathrm{~dB}$ & 1.3 to $2.3 \mathrm{GHz}$ \\
\hline Glass EpoxyFR4 & $-0.8384 \mathrm{~dB}$ & $-47.95 \mathrm{~dB}$ & 1.25 to $2.35 \mathrm{GHz}$ \\
\hline RT/Duroid 6006 & $-0.9926 \mathrm{~dB}$ & $-53.41 \mathrm{~dB}$ & 1.4 to $2.2 \mathrm{GHz}$ \\
\hline
\end{tabular}

It is obvious from table 5, that most suitable substrate for the designing of microstrip band-reject filter is RT/Duroid 6006 which provides wide bandwidth and improved insertion and return loss with compact structure as compared to other substrates.

\section{Conclusion}

In this paper three types of dielectric substrates are used for the performance and design comparison of Microstrip band-reject filters which is used for L-band applications. Scattering parameters are calculated from the simulated performance of the filter in terms of insertion and return loss. It is concluded that RT/Duroid 6006 is the best dielectric substrate for obtaining good bandwidth, better performance and compact size as compared to other two substrates.

\section{References}

[1] G. J. S. Hong and M. J. Lancaster, "Microstrip Filters for RF/Microwave Applications" (1/e), John Wiley \& Sons Inc, (2001).

[2] D. M. Pozar, "Microwave Engineering" (2/e), John Wiley, (2000).

[3] H. Jia-Sheng, "Microstrip Dual-Mode Band Reject Filter," IEEE Microwave Symposium, vol. 2, (2005), pp. 945-948

[4] T. Wei and Z. R. Hu, "Compact Left-handed Dual Mode Notch Bandstop Filter", IEEE MTT-S International Microwave Symposium Digest, (2006), pp. 1261 - 1264

[5] M. S. Yaqeen. E. T. Halil, "A New Narrow Band Dual-Mode Microstrip Slotted Patch Bandpass Filter Design Based on Fractal Geometry", 7th IEEE International Conference on Computing and Convergence Technology (ICCCT), (2012), pp. 1180 - 1184

[6] K. S. Vivek, G. S.Tomar, B. S. Sarita, "Optimum Design of Microstrip Band Stop Filters Using Artificial Neural Network", IJCSN 2012, ISSN 2234-8018, vol. 1, Iss 2, , Apr (2012), pp. 87-96

[7] L. Tan, L. Qiang, L. Ruijie and J. Teng, "Design of Transimpedance Low-pass Filters", Taylor \& Francis; International Journal of Electronics, vol. 100, (2013), pp. 142-149.

[8] X. Jin, J. Yu-Xue, C. Chun-Hong and W. Wen, "Compact and High Performance Bandpass Filter and Diplexer Based on SCMRC-loaded SIR", Taylors and Francis; International Journal of Electronics, vol. 100, (2013), pp. 1-13.

[9] S. Fallahzadeh, A. Akbarzadeh and M. Tayarani, "Spurious Response Suppression in Microstrip Bandpass Filters using Defected Microstrip Structures", Taylors and Francis; International Journal of Electronics, vol. 100, (2013), pp. 389-400.

[10] C. Young-Ho and Y. Sang-Won, "Design of Balanced Dual-Band Bandpass Filters using Asymmetrical Coupled Lines", IEEE Transactions on Microwave Theory \& Techniques, vol. 61, iss. 8, (2013), pp. 2814-2820.

[11] T. S. Geetam, K. S. Vivek and B. S. Sarita, “Artificial Neural Network Design of Stub Microstrip Bandpass Filters", International Journal of Ultra wideband Communication Systems, Inderscience publishers, ISSN 1758-7298, vol. 3, no. 1, (2014). pp. 38-49.

[12] K. S. Vivek, T. S. Geetam and B. S. Sarita, "Design of Grooved Microstrip Patch Resonator Filters for Mobile Communication", International Journal of Future Generation Communication and Networking, ISSN: 2233-7857, vol. 9, no. 5, (2016). pp. 131-142. 